\title{
A CAVERNA: UM RETRATO LITERÁRIO DA INSERÇÃO DO SUJEITO NO EMERGENTE MODELO DE PRODUÇÃO MODERNO
}

\author{
Monalisa Pontes Xavier* \\ Cássio Adriano Braz de Aquino** \\ Luciana Lobo Miranda***
}

\section{Resumo}

O presente texto realiza uma leitura da obra $A$ caverna, de José Saramago, buscando a interface dessa produção com questões concernentes à Psicologia. Mais especificamente, a relação entre o trabalho e sua influência no processo de produção de subjetividades. Com base na realidade literária retratada, o ensaio levanta questôes relativas ao advento da Modernidade (período histórico em que a narrativa se passa); a inserção do sujeito nessa nova época, caracterizada pelo modelo industrial de produção; e seu estabelecimento como modo de vida predominante das sociedades modernas. O cenário de transição para uma nova ordem social contextualiza o drama da família Algor. Além disso, aborda as metamorfoses sofridas pelo trabalho e que são impostas ao trabalhador, em virtude da organização sócio-histórica então emergente.

Palavras-chave: A caverna; trabalho; subjetividade; sociedades modernas.

* Professora assistente do Curso de Psicologia da Universidade Federal do Piauí, Doutoranda em Ciências da Comunicação pela Universidade do Vale do Rio dos Sinos (UNISINOS).

** Professor Adjunto do Departamento de Psicologia da Universidade Federal do Ceará (Graduação e Mestrado).

*** Professora Adjunta do Departamento de Psicologia da Universidade Federal do Ceará (Graduação e Mestrado). 


\begin{abstract}
THE CAVE: A LITERARY PORTRAIT OF THE SUBJECT INSERTION IN THE EMERGING MODEL OF MODERN PRODUCTION

This text makes a reading of The cave, by José Saramago, searching the interface of this production with questions concerning to Psychology, specifically the connection between work and its influence in the process of subjectivity production. Reality-Based literary portrayed, the essay raises questions about the advent of Modernity, historical period used as background of the storyline development, as well as the insertion of the subject in this new era, depicted by the industrial production model and the establishment of that model as a prevailing way of life of the modern societies. The transition scenario to a new social order composes the drama of the Algor family, broaching the metamorphosis suffered by the working, and which were imposed to the worker, in virtue of the emerging social-historical organization.
\end{abstract}

Keywords: The cave; work; subjectivity; modern societies.

\title{
INTRODUÇÃO
}

Diversos campos do saber trazem contribuições relevantes para a compreensão de questôes delegadas ao domínio da Psicologia. Tomando como base essa premissa, recorremos à Literatura para, a partir dela, desenvolvermos nossas reflexões relativas às metamorfoses ocorridas no mundo do trabalho e suas consequências na subjetividade humana.

Para tal, partimos da obra de José Saramago: A caverna. Esta traz um oleiro como protagonista. Este personagem vivencia a expansão da industrialização e a substituição do trabalho artesanal pelo trabalho industrial. Nesse movimento, toda a sua vida passa por intensas mudanças, ao passo que seu trabalho se torna desnecessário no "novo mundo" que se configura.

As transformaçôes vivenciadas por Cipriano Algor - o oleiro protagonista - não se limitam à sua atividade laboral, visto que seu trabalho reflete toda a sua existência: sua identidade, seu lazer, seu modo de produção e sua vida. Com isso, o "novo mundo" traz consigo uma série de elementos que impactam a existência da personagem, configurando-se como novos vetores de subjetivação.

A história de Cipriano Algor é também a história de todos os homens que vivenciam as metamorfoses do mundo trabalho e, diante delas, se veem destituídos de suas referências subjetivas, sejam essas mudanças em sua etapa primeira: a de substituição do trabalho artesanal pelo trabalho industrial, como se deu com o oleiro, ou as transformaçōes mais recentes: transmutação do trabalho industrial para o mundo "pós" industrial. 
O livro de Saramago ilustra, além do sofrimento do protagonista frente à nova realidade, o modo como o trabalho atua como vetor privilegiado de produção de subjetividades. Para compreendermos a relação estabelecida entre o trabalho e a produção de subjetividades, será exposto o que entendemos por subjetividade a partir da leitura de Félix Guattari, teórico francês no qual nos pautamos para trabalhar tal categoria.

Guattari entende a subjetividade como uma produção que se processa na transversalidade dos múltiplos elementos que compõem a vida dos homens, a exemplo do trabalho, do lazer, da cultura, da sexualidade e do inconsciente. A subjetividade é, pois, entendida como uma produção que se processa na interseção de duas dimensões: a dimensão interna e a dimensão histórico-social. Essas dimensões são indissociáveis e, paradoxalmente, inconciliáveis, como caracteriza Rolnik (1997). Na relação que se estabelece entre elas, se delineiam inúmeras possibilidades de existência; ilimitados perfis subjetivos.

A inter-relação entre a dimensão interna e a dimensão histórico-social marca o caráter de devir conferido às subjetividades. Assim, a subjetividade passa a ser compreendida como um sempre outro. Uma formação processual que encontra sentido e valor na interface com os múltiplos fatos que compóem a produção cultural. Dessa forma, ressaltamos, ainda, que a subjetividade - segundo um viés guattariniano - não deve ser entendida como algo que se encontra somente nos indivíduos. Ela também está no meio social, porém com ele não se confunde, como argumentam Guattari e Rolnik (1986):

Os processos de subjetivação não são centrados nos agentes individuais - funcionamento de instâncias intrapsíquicas, egoicas, microssociais - nem em agentes estritamente grupais. Esses processos são duplamente descentrados, implicando o funcionamento de máquinas de expressão que podem ser tanto de natureza extrapsíquica ou extraindividual quanto de natureza infra-humana, infrapsíquica, infrapessoal (Guattari e Rolnik, 1986: 31).

Com isso, Guattari retira a subjetividade do campo estritamente individual e passa a dimensioná-la no âmbito de todos os processos de produção social e material. Abdica, de uma vez por todas, da ideia de uma subjetividade da ordem do natural ou do universal. Contrariamente, também não se trata de uma subjetividade recipiente de coisas exteriores, pois o indivíduo também produz subjetividade no entrecruzamento das diversas vozes que compõem a sua vida.

Nesse entrelaçamento entre o individual e o social, nas mais diversas dimensões da vida, são produzidas as subjetividades. Portanto, este trabalho intenciona 
discutir como as metamorfoses do mundo do trabalho constituem novos vetores de subjetivação. Para tal, tomamos como base o caso literário de Cipriano Algor, narrado por Saramago em A caverna.

\section{Ao TRABAlHo...}

O livro narra a trajetória de Cipriano Algor, um oleiro que vive na época da industrialização e tem seu trabalho extinto em decorrência da expansão tecnológica. Ao dar-se conta de que em seu mundo não há mais lugar para o trabalho artesanal, ele passa a vivenciar conflitos relativos à sua identidade, ao valor da existência, à angústia de um homem sem lugar e desencaixado de sua realidade.

Seu genro, Marçal Gacho, é guarda do Centro. Ele espera uma promoção, que proporcionará à família a mudança para o referido local. Em virtude da promoção do genro, Cipriano Algor vê-se obrigado a morar no Centro. Este fato acentua seu penar frente à situação, já que não consegue se enquadrar nos padrões de "habitante do Centro" e viver segundo as normas do lugar.

Perpassado pelo relato acima descrito, o livro nos leva a pensar a inserção do homem no modo de produção industrial que caracterizou a Modernidade. Este, longe de ser somente um modelo de produção, configurou-se como o modo de vida das sociedades modernas.

O período histórico em questão - a Modernidade - aparece como marco inicial do enlace de tudo o que se entendia por trabalho com fins de sobrevivência, além de sua adequação às ideias que passaram a predominar na época, como: ideias de progresso e tecnologia entre outras. Todas elas moldadas pelo capital, que passou a ser o regulador social do momento.

Como argumenta Lara (2003: 47), esse novo regulador social "capturou para si a significação de tudo o que ele chamou de trabalho, colocando-o a seu serviço". $\mathrm{O}$ trabalho ganhou a conotação de trabalho assalariado, ficando restrito àquele capaz de proporcionar a valorização do capital e a geração de lucros.

Paralelamente à nova significação conferida ao trabalho, o trabalhador também foi ressignificado. Na figuração sócio-histórica moderna, o conceito de trabalhador se vê intimamente relacionado com o de cidadão; ambos constituem faces de uma mesma moeda. Só é cidadão o homem que trabalha e que, consequentemente, detém posses.

Esse movimento de alteração de significados do trabalho e do trabalhador, bem como sua inserção no novo modelo produtivo, é claramente vislumbrado no drama de Cipriano Algor. Isto pode ser observado quando Algor é destituído do 
lugar de trabalhador, já que a evolução tecnológica da produção traz consigo novas formas, mais práticas e lucrativas, de fabricação de louças. A louça de barro não mais interessava. Com isso, o oleiro também se fazia dispensável, como lamuria Cipriano Algor no seguinte fragmento da obra: "rirem-se do meu trabalho e do trabalho da nossa filha, dizem eles que as louças de barro deixaram de interessar, que já ninguém as quer, portanto também nós deixamos de ser precisos [...]" (Saramago, 2000: 45).

Observa-se que não foi só do papel de trabalhador que Cipriano Algor foi privado. A partir da perda do trabalho, ele se vê como um homem sem rumo, ameaçado em sua existência, como percebe a filha ao tomar conhecimento do que ocorreu ao pai: "[...] o que será ficar de repente sem trabalho, separar-se da casa, da olaria, do forno, da vida [...] Da vida [...]” (Saramago, 2000: 35). Separar-se da vida, na medida em que, no modelo artesanal, o trabalho determina todo o modo de viver. O sujeito é o artesão, no caso o oleiro; sua vida é a olaria. Assim contextualiza Albornoz (2000):

No artesanato, o trabalho não obedece a nenhum motivo ulterior além da fabricação do produto e dos processos de sua criação: a esperança de fazer um bom trabalho, realizar um produto, a arte de fazê-lo. Os detalhes do trabalho cotidiano são significativos, não estão separados do produto do trabalho. $\mathrm{O}$ trabalhador é livre para organizar seu trabalho, quanto ao plano, começo, forma, técnica e tempo. Ao trabalhar, o artesão pode aprender a desenvolver seus conhecimentos e habilidades; o seu trabalho é um meio de desenvolver habilidades. Não há separação entre trabalho e divertimento, trabalho e cultura (Albornoz, 2000: 39).

O trabalho, à época dos Algor(es), muito além de meio de subsistência, era também fonte de significação social, de identidade, de reconhecimento. O trabalho constituía um modo de subjetivação, um lastro para a existência não só pessoal, mas também familiar, já que a profissão era herdada e fazia parte da tradição da família. O avô de Cipriano foi oleiro, assim como o pai, e por essa profissão a filha já se encaminhava. O traço de uma linearidade no trabalho também é destacado, embora com outros matizes, por Sennett (2000). Ainda que estabelecendo um paralelo entre o modelo salarial e a emergência de um capitalismo flexível, fica evidente que a proposta de significação social atribuída pela atividade de Algor, encaminhava-se a uma "sequência de naturalização" de um modo de vida, que de alguma forma foi estabelecida na sociedade dita salarial na forma de "carreiras estáveis". Se no modo de produção "artesanal” essa significação era plena, no modelo 
industrial associou-se às carreiras e, no contexto de instabilidade contemporânea, tornou-se um mal a expurgar.

Ameaçado pelo desinteresse frente ao seu produto, o oleiro dirige-se ao mesmo lugar em que sua mulher morreu, dando indícios de que, naquele momento, sua vida também tivera fim: "Cipriano Algor já tinha saído, estava na olaria, sentado a um dos tornos, de cabeça baixa. Fora ali que uma parada cardíaca fulminante cortara a vida de Justa Isasca" (Saramago, 2000: 66).

A mudança para o Centro representava o abandono da tradição, a quebra com os laços parentais e o fim de uma história construída ao longo de gerações: "[...] tudo ali estava coberto de barro, não sujo de barro, somente da cor que ele tem, da cor de todas as cores que saiu da barreira, o que foi sendo deixado por três gerações que todos os dias mancharam as mãos no pó e na água do barro [...]" (Saramago, 2000: 35).

Representava, também, a angústia perante a vida de um homem que se viu desterritorializado ${ }^{1}$ de suas referências subjetivas, como se percebe na fala do protagonista:

[...] é o trabalho que deixou de ser o que havia sido, e nós, que só podemos ser o que fomos, de repente percebemos que já não somos necessários no mundo, se é que alguma vez o tínhamos sido antes, mas acreditar que o éramos parecia bastante, parecia suficiente, e era de certa maneira eterno pelo tempo que a vida durasse, que é isso a eternidade, nada mais do que isso (Saramago, 2000: 106).

A significação atribuída pelo oleiro ao seu trabalho encontrava-se esvaziada de sentido, este já não mais existia. A vocação transmitida pelo pai e pelo avô não tinha mais utilidade, assim como as peças de louça que seriam destruídas: “[...] dura tarefa de ter de destruir os frutos do meu próprio trabalho, que é o mesmo que destruí-los não ter a quem os vender, e, pior ainda, não achar quem os queira, mesmo dados" (Saramago, 2000: 125).

A ideia de vocação, à qual o trabalho estava associado, também se viu esfacelada. Sua relação com realização pessoal, como eixo de uma vida digna, fonte de orgulho e respeito deixa de existir, sendo convertida, como afirma Bauman (1999b):

O trabalho como vocação se converteu em privilégio de poucos, numa marca distintiva da elite, num modo de vida que a maioria observa, admira e contempla à distância, mas experimenta de forma substituta através da literatura barata $\mathrm{e}$ da realidade virtual das telenovelas. À maioria é negada a oportunidade de viver seu trabalho como uma vocação (Bauman, 1999b: 60; tradução livre). 
Cipriano Algor e sua família eram chamados a viver uma nova vida, aquela que passaria a predominar a partir de então. Todos os oleiros, todos os artesãos, todas as pessoas do campo, cedo ou tarde, seriam agregados às normas de funcionamento do Centro. Marçal assim já estava acostumado, já tinha seu trabalho fisgado pelo modelo que se tornava hegemônico. O guarda do Centro trabalhava por dez dias, depois dos quais gozava de 40 horas de folga para dedicar-se à família, ao lazer e aos afazeres pessoais. Após a promoção a guarda residente, Marçal Gacho deveria morar no Centro, nos apartamentos reservados para os funcionários e suas famílias (desde que estas não fossem numerosas).

A atividade profissional do genro de Cipriano Algor exemplifica mais uma modificação sofrida pelo trabalho no período moderno. Ou seja, a vinculação dessa atividade à ideia de coação, esta entendida tanto no sentido de coação social como de coação natural. Como explica Lara (2003: 13), coação social no sentido de que não há outra escolha a não ser trabalhar. E coação natural, na medida em que "se tem que se submeter à maldição do trabalho, comendo o pão com o suor do próprio rosto".

Em $A$ caverna, observa-se como o trabalho passa a ser coercitivo. Ao sujeito não é mais possibilitado manter-se a partir de um fazer artístico e em conformidade com as tradiçôes. Pelo contrário, lhe é imposto um modelo de trabalho que o aprisiona e segundo o qual o homem passa a ser dependente, pois somente através dele é possível garantir sua subsistência. A esse caráter coercitivo soma-se ainda a organização panóptica da sociedade, fundamental no estabelecimento do modelo industrial. No livro, a figura de poderes controladores e o panoptismo, tematizados por Michel Foucault $(1987,2005)$, se faz presente.

O panóptico é apresentado por Foucault a partir das formulações do jurista britânico Jeremy Bentham, ainda no século XVIII, e divulgado como uma verdadeira "ortopedia social” (Foucault, 2005: 86) no século XIX. O panóptico representa uma prisão modelar, onde prisioneiros eram colocados em celas individuais e em círculo ao redor de uma torre central que, a partir de um cálculo de abertura das janelas, as colocavam num regime de total visibilidade. Todos os prisioneiros eram visíveis àquele que vigiasse. No entanto, a recíproca não era verdadeira. Diante da onipresença da torre central, numa economia da visibilidade, com vigias protegidos por biombos e persianas, tinha-se a impressão permanente de ser vigiado. Para Foucault, mais do que uma estratégia arquitetônica circunscrita ao regime penal, o panoptismo acabou por se transformar em um dos traços característicos da sociedade disciplinar, sociedade onde o trabalho industrial passou a ser um ícone: 
É uma forma de poder que se exerce sobre os indivíduos em forma de vigilância individual e contínua, em forma de controle de punição e recompensa e em forma de correção, isto é, de formação e transformação dos indivíduos em função de certas normas. Este tríplice aspecto do panoptismo - vigilância, controle, correção - parece ser uma dimensão fundamental e característica das relações de poder que existem em nossa sociedade (Foucault, 2005: 103).

A normatização das instâncias controladoras pode ser verificada na relação de Cipriano Algor e seu genro com os poderosos do Centro, a quem os personagens submetem seu trabalho. Todas as suas ações dependem da autorização de um chefe, previamente instruído e legitimado para tal, como exemplifica a seguinte passagem: "Poderei começar a vender aos comerciantes da cidade, é questão de o Centro autorizar [...]" (Saramago, 2000: 34). A delegação de poderes a instituições disciplinadoras - uma das quais é representada pela indústria e, na obra de Saramago, pelo Centro - destitui o homem do poder sobre o seu trabalho. O trabalho é transformado em mercadoria, competindo seu valor aos "donos do capital".

A alegoria do Panóptico, por sua vez, aparece no olhar sempre presente dos guardas dirigido aos frequentadores do Centro. Como discorre Bauman (1999a: 56), "o Panóptico não permitiria qualquer espaço privado; pelo menos nenhum espaço privado opaco, nenhum sem supervisão ou, pior ainda, não passível de supervisão". Os transeuntes eram constantemente vigiados e a curiosidade era inadmissível. O conhecimento do que se passava era privado das pessoas que viviam aquela realidade, a elas era permitido apenas viver. Saber o quê, como, ou o porquê do que se passava consistia em tarefa que não lhes devia competência.

Para essa realidade, que se firmava como nova diretriz da organização social, Cipriano Algor foi transferido. Deixou para trás a olaria, as tradições, o cão Achado, que não seria aceito no Centro, e sua nova dona, Isaura Madruga, mulher por quem o oleiro se enamorara. Embora relutasse, era preciso mudar de vida e entrar em sintonia com a situação que se lhe impunha. Era preciso despir-se da roupa da olaria e vestir a nova roupa, aquela que o impregnaria e passaria a moldar seus dias:

[...] o que está a suceder é algo como despirmo-nos de uma roupa para vestir outra, uma espécie de carnaval mascarado, Sim, observou o pai, aparentemente é assim, mas, ao contrário daquilo que geralmente se cria e sem pensar se afirmava, o hábito faz realmente o monge, a pessoa também é feita pela roupa que leva, poderá não se notar logo, mas é só questão de dar tempo ao tempo (Saramago, 2000: 282). 
A passagem supracitada, na qual Cipriano Algor e sua filha discutem a construção do homem em conformidade com a roupa que leva, remete à questão da constituição subjetiva dos indivíduos a partir da configuração sócio-histórica na qual se encontram imersos. Com Guattari e Rolnik (1986), pode-se conceber que todo tipo de ordem social produz um modelo correspondente de produção de subjetividades. E o sucesso de cada ordem relaciona-se diretamente com a eficiência com que as subjetividades são por elas moldadas. Como afirma o autor: "a produção de subjetividade talvez seja mais importante do que qualquer outro tipo de produção [...]" (Guattari \& Rolnik, 1986: 26). Contextualizando à sua época, prossegue:

No Japão, por exemplo, não se tem petróleo mas se tem - e como! - uma produção de subjetividade. É essa produção que permite à economia japonesa se afirmar no mercado mundial, a ponto de receber a visita de centenas de delegaçōes patronais que pretendem "japoniza” as classes operárias de seus países de origem (Guattari \& Rolnik, 1986: 26).

O Centro, do livro de Saramago, vem a ser o Japão proferido pelos autores acima. O local para onde foi Cipriano Algor e sua família funciona como uma fábrica. Esta, entretanto, não produz mercadorias; encontra-se a produzir novas formas de vida, novas modos de subjetivação, novos homens - embora estes venham a ser, posteriormente, concebidos como análogos à mercadoria.

Nesse ponto - na eficácia do processo de fabricação de subjetividades - encontra-se o êxito do Centro e também do modelo industrial de produção. Este, para proclamar sua hegemonia, precisava não apenas lucrar ou englobar as pessoas como mão-de-obra, mas educá-las, socializá-las segundo sua lógica. Ou seja, criar subjetividades dedicadas ao trabalho industrial, ao fortalecimento e disseminação desse modelo que, a partir de então, legitimava a existência dos homens.

Concebe-se, com isso, que o novo modelo industrial, "ao propor seus valores e seu processo de socialização, seu imaginário enganador, tem por fim englobar todos os participantes numa fantasia comum" (Enríquez, 2001: 175). Assim funciona a máquina que produz a subjetividade industrializada. Que dita ao homem, que busca um lugar nesse mundo que se lhe apresenta, como deve ser, o que deve fazer e por qual caminho deve seguir.

Somente assim - por meio da produção capitalística² da subjetividade - é, como afirmam Guattari e Rolnik (1986: 39), "que as classes e castas que detêm o poder nas sociedades industriais tendem a assegurar um controle cada vez mais 
despótico sobre os sistemas de produção e de vida social". O controle sobre o qual se está discorrendo passa a fazer parte do cotidiano do homem industrial, como já exemplificado pelo panoptismo e pelas instituições disciplinadoras. Esse controle ainda se faz presente na tentativa de supressão da singularidade, da eliminação das diferenças, na inserção desse homem num modo de vida padronizado e préfabricado, no qual o apartamento reservado a Marçal Gacho e sua família serve de metáfora: "Os apartamentos estavam identificados como se fossem habitações de hotel” (Saramago, 2000: 279).

Outra vez faz-se uso das palavras de Guattari e Rolnik (1986: 40) para contextualizar a cena do livro: "a tendência atual é igualar tudo através de grandes categorias unificadoras e redutoras [...] que impedem que se dê conta dos processos de singularização". A comparação do lugar de moradia com um hotel expressa a impessoalidade com que as pessoas são recebidas no Centro. Ao novo lar não é permitido levar nada além do indispensável. Os apartamentos já são mobiliados e têm toda a estrutura necessária para receber os moradores.

Assim como o aparato produtivo e social, as formas de relacionamento são também fruto da ordem capitalística, que "fabrica a relação do homem com o mundo e com ele mesmo". Além de se projetar na realidade, impondo-a, como "a ordem do mundo, ordem que não pode ser tocada sem que se comprometa a própria ideia de vida social organizada” (Guattari \& Rolnik, 1986: 42). Ordem essa não bem aceita por Cipriano Algor. Os dias do protagonista no Centro eram gastos com idas e vindas; perambulações que espelhavam o seu desconforto frente ao "não-lugar" que o Centro representava. À espera do porvir, o ex-oleiro passava o dia a vagar, dando mostras de quão perdido estava naquele espaço que não era seu. Anônimo, como alguém que deixou de ser, caminhava pelos corredores e passadiços fingindo ser o que não era, já que fora privado de sua identidade, porém resistindo a deixar de ser o que um dia fora.

A resistência da personagem às normas do local que o abrigava algumas vezes lhe foi motivo de censura, causando temor ao genro. Este lhe pedia respeito às regras, sob pena de que, por alguma atitude indevida do sogro, viesse a perder o emprego. Porém a mesma resistência que resultou em preocupação a Marçal levou Cipriano Algor à descoberta do grande segredo. Sabendo que algo estranho se passava, o sogro do guarda residente deu vazão a sua curiosidade e dirigiu-se até o lugar onde o genro velava "o desconhecido". Lá encontrou uma imensa gruta, no interior da qual deparou-se com a imagem fantástica: 
Surgiu-lhe, num instante, o que parecia um banco de pedra, e logo, no instante seguinte, alinhados, uns vultos mal definidos apareceram e desapareceram... tocou ao de leve uns panos escuros, subiu, e era um corpo humano sentado o que ali estava. Ao lado dele, cobertos com os mesmos panos escuros, mais cinco corpos igualmente sentados, erectos todos como se um espigão de ferro lhes tivesse entrado pelo crânio e os mantivesse atarraxados à pedra. [...] aproximouse mais, [...] este é homem, esta é mulher, outro homem, outra mulher, três homens e três mulheres, viu restos de ataduras que pareciam ter servido para lhes imobilizar os pescoços (Saramago, 2000: 332).

A imagem que vira causou a Cipriano Algor um misto de confusão e descrença. Seria real aquilo que vira? Não o podia ser. Como não, se o tinha tocado? O que a personagem encontrou, aprisionado na caverna, foi a si mesmo e aos seus. Pessoas presas a uma realidade que desconheciam, mas que as absorvia. Não era suportável perceber como, na condição de "homem do Centro", aqueles seres eram capturados e atados, sem possibilidades de salvação.

Ainda era tempo de escapar? Para Cipriano Algor, sim. A personagem foge antes de ser inserido na vida industrial que emergia, sob pena de nela ficar aprisionado à semelhança da imagem da caverna. Imagem que retrata as subjetividades constituídas no modelo do Centro e ali presas, amarradas sem ter como sair. Para a maioria das pessoas, a possibilidade de fuga já lhes tinha sido vetada. Como poder dominante e capaz de tudo explicar, o Centro também engloba a caverna na sua realidade. E a lança como mais uma produção sua, apresentando-a ao público de forma que não viesse a causar estranhamento: "Brevemente, abertura ao público da caverna de Platão, atracção exclusiva, única no mundo, compre já sua entrada" (Saramago, 2000: 350). A cooptação de tudo que se apresenta à realidade pelo modelo que fabrica as subjetividades, como é ilustrado no fragmento acima, ratifica mais uma vez o anunciado por Guattari e Rolnik (1986), quando afirmam:

Estou convencido de que se alguns extraterrestres desembarcassem amanhã em São Paulo, haveria experts, jornalistas e especialistas de toda espécie para explicar às pessoas que no fundo não é uma coisa tão extraordinária assim, que já se tinha pensado nisso, que até já existia há muito tempo uma comissão especializada no assunto e, sobretudo, que não há por que se afobar, pois o poder está aí para se ocupar disso (Guattari e Rolnik, 1986: 43). 


\section{CONSIDERAÇÕES FINAIS}

A obra A caverna serviu de cenário, até o momento, para uma discussão acerca da emergência do modelo industrial de produção, bem como das consequências que seu estabelecimento trouxe para o homem daquela época. Entretanto, não se restringem à Modernidade as reflexões por ela suscitadas.

O livro de Saramago, aqui abordado, também fornece elementos para pensarmos a realidade contemporânea, o homem "pós" moderno em sua relação com o trabalho. Esse homem que, à semelhança de Cipriano Algor, vive um momento de transição e se vê sem lugar, experimentando um desencaixe frente ao fato social que o absorve.

O protagonista sofre a desadaptação diante de uma nova forma de produção subjetiva. Fruto de uma formação cultural anterior à chegada das indústrias e das tecnologias, o oleiro acompanha o desaparecimento de uma forma de vida que foi sua, vendo-a se dissolver e sobrevivendo à sua dissolução.

Também assim encontram-se os homens de hoje. Subjetividades constituídas no modelo industrial, educadas para o trabalho assistem atualmente a sua fragmentação, saboreando a incerteza do que se lhes apresenta. A educação desses sujeitos pressupunha que todos deveriam ser produtores. Essa função, entretanto, não é mais o imperativo social. A nova ordem que lhes chega é o consumo de bens, exclusivos e diferenciados para cada um deles. Do capitalismo voltado para a produção, uma nova ordem capitalística com ênfase no consumo. Do contexto disciplinar descrito por Foucault passamos para uma sociedade de Controle (Deleuze, 1992).

Em seu breve, porém visionário, ensaio, o filósofo analisa as formas de controle emergentes na sociedade contemporânea. Aparentemente mais flexíveis e fluidas, elas ultrapassam a vigilância restrita aos "meios de confinamento: escola, fábrica, manicômio e instaura[m] um novo regime de controle a céu aberto, as máquinas de visão, câmeras instauradas que induzem a formas "ultrarrápidas de controle ao ar livre" (Deleuze, 1992: 220).

No contexto do trabalho, ao invés do salário fixo, a modulação através do salário de acordo com a produtividade. Ao invés da separação escola-trabalho, a formação permanente. Ao invés do exame, o controle contínuo. Diz Deleuze: "O controle é de curto prazo e de rotação rápida, mas também contínuo e ilimitado, ao passo que a disciplina era de longa duração, infinita e descontínua" (Deleuze, 1992: 224).

O cenário trabalhista contemporâneo, distintamente daquele no qual esses indivíduos foram socializados, atravessa um momento de transformação das relações produtivas, de flexibilização da produção e de precarização do emprego. $\mathrm{O}$ 
trabalho é redefinido, exigindo também uma reformulação do que se entende por trabalhador. O novo perfil exigido para os trabalhadores define não apenas "modos de trabalhar, mas modos de ser":

A contemporaneidade propõe, portanto, uma flexibilização em relação ao próprio conceito de trabalho, não fixando apenas o emprego, mas considerando também outras formas de contratos, como serviço de terceirização, o trabalho autônomo, informal, temporário, voluntário, as cooperativas e os estágios. Da mesma forma, a importância de operar com o conceito de "qualidade" em todas as funções [...] mostra-se como outra condição insistentemente marcada. A demanda é que tais conceitos sejam encarnados na maneira de ser e agir dos trabalhadores (Giacomel, Ghisleni, Amazarray \& Engelman, 2003: 138).

Nesse contexto, o homem que teve sua vida estruturada com base na produção industrial (modelo de produção econômica e de fabricação de subjetividades) questiona-se o que dele será.

Novamente, voltamos a Cipriano Algor, à imagem do ex-oleiro caminhando no Centro, analogamente às pessoas do nosso tempo, sem lugar, perdidas em sua forma de ser, caminhando como se fugissem de alguma coisa. Essas pessoas que passam a vida a vagar entre o consumo de objetos e atitudes, procurando uma identidade e um lugar que lhes sirva de referência.

Possibilidades de fuga tornam-se cada vez mais escassas. E o que fazer diante dessa situação? Descrer no mundo em movimento e nas novas realidades que se impõem? Deleuze, ao comparar Sociedades Disciplinares às Sociedades de Controle na atualidade, dissera: "Não se deve perguntar qual é o regime mais duro, ou o mais tolerável, pois é em cada um deles que se enfrentam as liberações e as sujeições" (Deleuze, 1992: 220).

As novas formas de inserção laboral, exatamente porque carecem de qualquer referência, podem acabar por permitir diferentes possibilidades de escape. Enquanto o trabalho da sociedade salarial/industrial estabelecia uma forma de disciplinamento nítido, o momento contemporâneo foge a qualquer tentativa de modelização.

Trata-se, entáo, de enxergar novos possíveis ou, assim como faz Guattari, almejar a abertura dos campos de existência para a processualidade que se expressa na ideia de devir. Com isso, o pensador francês nos permite vislumbrar a possibilidade de ultrapassamento da ordem instituída e de consecução do movimento de singularização. Tal movimento diz respeito à recusa das modelizaçóes, da serialização e do achatamento subjetivo imposto pela ordem vigente, quando de sua tomada da subjetividade como mais um campo de sua produção. 
Singularizar é advogar em prol da superação de todo e qualquer estado paralisante e aprisionador; se contrapor à cooptação da totalidade da vida pela lógica do mercado; ir de encontro à mercantilização da existência; resgatar a dimensão da utopia... É, ainda, emergir como subjetividade autorreferenciada; retomar a capacidade de conferir novos sentidos à existência; estar aberto ao diferente; viver a processualidade - o devir e as linhas de fuga - num movimento contínuo de criação.

Esse é o grande desafio que se atribui ao homem "pós" industrial: deparar-se com a sua caverna e diante dela não ficar paralisado, mas, assim como Cipriano Algor, ao dar-se conta de que o prisioneiro da cena é ele próprio, motivar-se na busca de possibilidades de desvio, na construção de linhas de fuga que nos façam acreditar na construção de novos possíveis.

\section{REFERÊNCIAS}

Albornoz, S. (2000). O que é trabalho. São Paulo: Brasiliense.

Bauman, Z. (1999a). Globalização: as consequências humanas. Rio de Janeiro: Jorge Zahar Editor.

Bauman, Z. (1999b). Trabajo, consumismo y nuevos pobres. Barcelona: Gedisa.

Deleuze, G. (1992). Post-scriptum sobre as sociedades de controle. In: Conversações. Rio de Janeiro: Editora 34.

Enriquez, E. (2001). Interioridade e organizaçōes. In: Dave, E. \& Vergara, S. C. (Orgs.). Gestão com pessoas e subjetividade (pp. 173-187). São Paulo: Atlas.

Foucault, M. (1987). Vigiar e punir. Petrópolis: Ed. Vozes.

Foucault, M. (2005). A verdade e as formas jurídicas ( $3^{\mathrm{a}} \mathrm{ed}$.). Rio de Janeiro: Nau.

Giacomel A. E., Ghisleni, A. P., Amazarray, M. R. \& Engelman, S. (2003). Trabalho e contemporaneidade: $\mathrm{O}$ trabalho tornado vida. In: Fonseca, T. \& Kirst, P. (Orgs.). Cartografias e devires: a construçāo do presente (pp. 137-148). Porto Alegre: UFRGS.

Guattari, F. \& Rolnik, S. (1986). Micropolitica: cartografias do desejo. Petrópolis: Vozes.

Lara, X. (2003). Trabalho, educação, cidadania: reflexōes a partir de educação entre trabalhadores. Rio de Janeiro: Capina/Ceris/Mauad.

Rolnik, S. (1997). Uma insólita viagem à subjetividade: fronteiras com a ética e a cultura.

In: Lins, D. (Org.). Cultura e subjetividade: saberes nômades (3a ed., pp. 25-34). São Paulo: Papirus.

Saramago, J. (2000). A caverna. São Paulo: Companhia das Letras.

Sennett, R. (2000). La corrosión del carácter. Barcelona: Anagrama. 


\section{Notas}

1 O termo território utilizado pelo filósofo e psicanalista francês Félix Guattari e seus desdobramentos, territorialização, desterritorialização e reterritorialização, dizem respeito às configuraçōes existenciais, a um espaço vital e não a locais demarcados geograficamente: "O território pode ser relativo tanto a um espaço vivido, quanto a um sistema percebido no seio do qual um sujeito se sente 'em casa' [...]. Ele é o conjunto dos projetos e das representações nos quais vai desembocar, pragmaticamente, toda uma série de comportamentos, de investimentos, nos tempos e nos espaços sociais, culturais, estéticos, cognitivos” (Guattari \& Rolnik, 1986: 323). Segundo Guattari o capitalismo foi responsável por conseguir atingir culturas que teriam conseguido escapar até dos rolos do cristianismo. Este movimento de desterritorialização, sob a égide do Capital, instaura uma remodelização nas faculdades mentais como peças compatíveis com a dinâmica social dominante, lançando uma sobrecodificação, o fetichismo do lucro.

2 O termo capitalístico é usado por Guattari para designar um tipo de subjetividade que se encontra ancorada em dispositivos capitalistas, no entanto não diz respeito somente a subjetividades produzidas em sociedades capitalistas. Como define Rolnik: "Guattari acrecenta o sufixo "ístico" a capitalista por lhe parecer necessário criar um termo que possa designar não apenas as sociedades qualificadas como capitalistas, mas também setores do "Terceiro Mundo" ou do capitalismo "periférico", assim como as antigas economias ditas socialistas dos países do leste, que viveram numa espécie de dependência e contradependência do capitalismo. Tais sociedades, segundo Guattari, em nada se diferenciaram do ponto de vista de produção de subjetividade. Elas funcionaram segundo uma mesma cartografia do desejo no campo social, uma mesma economia libidinal-política. (Guattari \& Rolnik, 1986: 15).

Recebido em 27 de junho de 2009 Aceito para publicação em 10 de março de 2010 